\title{
Reševanje problema LABS s pomočjo porazdeljenega računalniškega sistema in spletnega brskalnika
}

\author{
Niko Kovačič \\ Univerza v Mariboru \\ Fakulteta za elektrotehniko, \\ računalništvo in informatiko \\ Koroška cesta 46, SI-2000 \\ Maribor, Slovenija \\ niko@fsresitve.si
}

\author{
Janez Brest \\ Univerza v Mariboru \\ Fakulteta za elektrotehniko, \\ računalništvo in informatiko \\ Koroška cesta 46, SI-2000 \\ Maribor, Slovenija \\ janez.brest@um.si
}

\author{
Borko Bošković \\ Univerza v Mariboru \\ Fakulteta za elektrotehniko, \\ računalništvo in informatiko \\ Koroška cesta 46, SI-2000 \\ Maribor, Slovenija \\ borko.boskovic@um.si
}

\section{POVZETEK}

V članku smo predstavili porazdeljen sistem, ki s pomočjo spletnega brskalnika in programskega jezika JavaScript rešuje problem LABS. Za reševanje problema smo uporabili algoritem lssOrel. Ta algoritem je trenutno najboljši za reševanje tega problema. Zaustavitveni pogoj za reševanje določene velikosti problema smo načrtovali glede na najslabše dosežene rezultate med 100 neodvisnimi zagoni. Iz dobljenih rezultatov smo ugotovili, da spletni brskalnik lahko učinkovito uporabimo znotraj porazdeljenega sistema. Program se znotraj tega sistema izvaja nekoliko počasneje kot v primeru programa, ki je implementiran v programskem jeziku $\mathrm{C}++$. Ker pa imamo na voljo veliko število brskalnikov oz. odjemalec, lahko zaženemo več nalog programa hkrati. Če imamo na voljo dovolj odjemalcev, lahko dosežemo tudi boljše rezultate. To smo potrdili v prototipnem sistemu, kjer smo potrdili vse najboljše rešitve problema LABS do velikosti $L=149$.

\section{Kjučne besede}

Porazdeljeni sistem, problem LABS, spletni brskalnik, JavaScript

\section{UVOD}

$\mathrm{V}$ današnjem povezanem svetu so računalniški viri dostopni vsakomur, ki najde preprost način za njihovo pridobivanje. Porazdeljeni sistemi po načelu odjemalec/strežnik večinoma uporabljajo posebne namizne programe, s katerimi si lahko delijo računalniški viri. Tako se lahko ustvari omrežje, ki je sposobno procesirati veliko količino podatkov in preiskovati ogromne iskalne prostore brez uporabe superračunalnikov.

Ključna značilnost takšnega omrežja je preprostost njegove uporabe, saj lahko le tako dosežemo dovolj veliko število uporabnikov in s tem veliko procesorsko moč. Veliko lažje bi bilo, da uporabniki ne bi prenašali nobene programske opreme več, kot je to potrebno pri klasičnih porazdeljenih računalniških sistemih. To predstavlja preveliko pregrado za uporabnika, ki navadno prej obupa in opusti nameščanje potrebne programske opreme. Zato smo raziskali programsko opremo, ki jo ima uporabnik že nameščeno na svojih napravah ter kako bi jo lahko uporabili kot odjemalca.

Za najbolj primernega se je izkazal spletni brskalnik, saj je prednaložen na večini operacijskih sistemov, tudi na mobilnih napravah, kot so pametni telefoni in tablice. Vsi spletni brskalniki podpirajo interpretirani programski jezik JavaScript, s katerim razvijemo spletne aplikacije, ki lahko dostopajo do procesorskih virov. Hitrost izvajanja programov, implementiranih v jeziku JavaScript, se je v zadnjih letih precej izboljšala. To je omogočilo razvoj porazdeljenih sistemov za izvajanje algoritmov v spletnem brskalniku. Tako bomo tudi mi v našem sistemu uporabili jezik JavaScript znotraj spletnega brskalnika za reševanje problema LABS.

Iskanje binarnih sekvenc z največjim faktorjem F (angl. merit factor), znanega tudi kot low autocorrelation binary sequence $(L A B S)$ problem, predstavlja velik računski izziv. Za zmanjšanje računskih omejitev problema smo upoštevali algoritme, ki obravnavajo sekvence lihih velikosti $(L)$. Posledično nekatere rešitve ne bodo optimalne. Za algoritem smo izbrali lssOrel 8], saj je prikazal najboljšo zmogljivost.

Članek je organiziran na naslednji način. V 2. poglavju predstavimo sorodna dela. Nato implementacijo porazdeljenega sistema opišemo v 3. poglavju. Sledijo rezultati v 4. poglavju in članek zaključimo v 5. poglavju.

\section{SORODNA DELA}

Do sedaj je bilo že kar nekaj uspešnih porazdeljenih računalniških sistemov, ki so uspeli privabiti veliko število odjemalcev za reševanje računsko zahtevnih problemov. Eden izmed bolj znanih je SETI@home [6], katerega namen je analizirati radijske signale, v katerih bi lahko bili znaki zunajzemeljske inteligence. Uporablja programsko platformo BOINC, katero gostujejo na kalifornijski univerzi Berkeley.

Med prvimi porazdeljenimi sistemi, ki se uporabljajo v znanstvene namene, je Great Internet Mersenne Prime Search (GIMPS) 3], katerega cilj je iskanje Mersennovih praštevil. GIMPS se opira na Lucas-Lehmerov preizkus praštevil ter uporablja fazo poizkusnega deljenja, ki hitro eliminira 


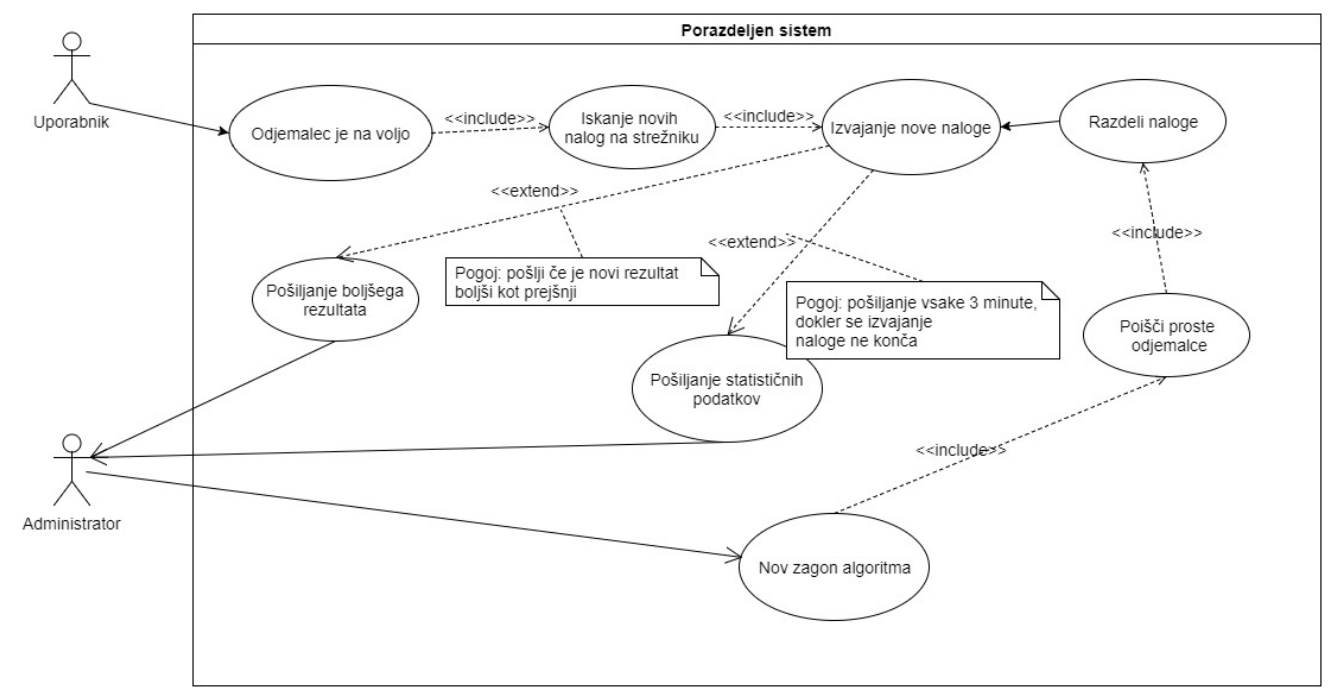

Slika 1: Diagram primerov uporabe porazdeljenega sistema.

Mersennova števila z manjšimi faktorji, ki predstavljajo velik delež kandidatov. S pomočjo sistem GIMPS so do sedaj našli 15 Mersennovih praštevil.

$S$ prihodom kriptovalut je postalo razdeljevanje nagrad za opravljeno računsko delo veliko lažje. Z njihovo pomočjo bo projekt Golem [2] poskušal postati decentraliziran superračunalnik in s tem globalni trg računalniških virov. Naročnik bo s povezovanjem računalnikov v porazdeljen sistem lahko najel vire od drugih uporabnikov, ki se nato uporabljajo za izvedbo nalog. Plačila se izvajajo na transakcijskem sistemu, ki je osnovan na Ethereum ter omogoča neposredne transakcije med uporabniki in naročniki.

V članku 9 so pokazali, da je možno uporabljati spletne brskalnike za izvajanje porazdeljenih algoritmov, kar nam je dalo dodatni zagon pri načrtovanju in implementaciji porazdeljenega sistema, opisanega $\mathrm{v}$ tem članku.

\section{LABS}

Problem neperiodičnih binarnih zaporedij z nizkimi avtokorelacijami lahko opišemo $\mathrm{z}$ binarno sekvenco dolžine $L$ :

$$
S=s_{1} s_{2} \ldots s_{L}, s_{i} \in\{+1,-1\} .
$$

Energijo sekvence in faktor $F$ izračunamo $\mathrm{z}$ uporabo naslednjih enačb:

$$
\begin{aligned}
E(S) & =\sum_{k=1}^{L-1} C_{k}^{2}(S), \\
C_{k}(S) & =\sum_{k=1}^{L-1} s_{i} s_{i+k} . \\
F(S) & =L^{2} /(2 E(S))
\end{aligned}
$$

Cilj reševanja problema je minimizirati energijo oz. maksimirati vrednost faktorja $F$. Iskanje binarnih sekvenc z najboljšim faktorjem $F$ ima pomembno vlogo pri reševanju tehničnih problemov na področju komunikacij.

\section{APLIKACIJA}

Implementacijo porazdeljenega sistema smo načrtovali tako, da bo podpiral naslednje funkcionalnosti:

- Anonimna uporaba in hitra registracija uporabnika.

- Izvajanje algoritmov v varnem okolju (angl. sandbox) znotraj JavaScript okolja v brskalniku.

- Prenašanje rezultatov iz odjemalca na strežnik.

- Dodeljevanje nalog iz strežnika na odjemalce.

- Prikaz izvajanja algoritma uporabniku na intuitiven način.

Postopek implementacije smo razdelili v več faz:

- Načrtovanje podatkovnega modela.

- Izbira ogrodij za razvoj spletnih aplikacij.

- Implementacija zalednega sistema (angl. backend).

- Implementacija algoritma lssOrel v jeziku JavaScript.

- Implementacija uporabniškega vmesnika.

- Implementacija nadzorne plošče.

Porazdeljen računalniški sistem začne nov zagon algoritma po ukazu administratorja na nadzorni plošči. Vsak nov odjemalec pošlje povpraševanje na strežnik, le ta pa mu posreduje naloge ali pa ga postavi v stanje pripravljenosti, kjer čaka na delo. Vsak odjemalec posreduje strežniku informacije o napredku reševanja problema. To posredovanje se izvaja vsakih 5 minut ali ko se najde novo najboljša rešitev. $\mathrm{Na}$ tak način se izognemo prekomerni komunikaciji med odjemalcem in strežnikom. Ker uporabljamo stohastične algoritme, se vsakemu odjemalcu dodeli unikatno seme. Seme uporablja odjemalec, da inicializira generator naključnih števil. S tem se izognemo, da bi odjemalci reševali problem na enak način. 


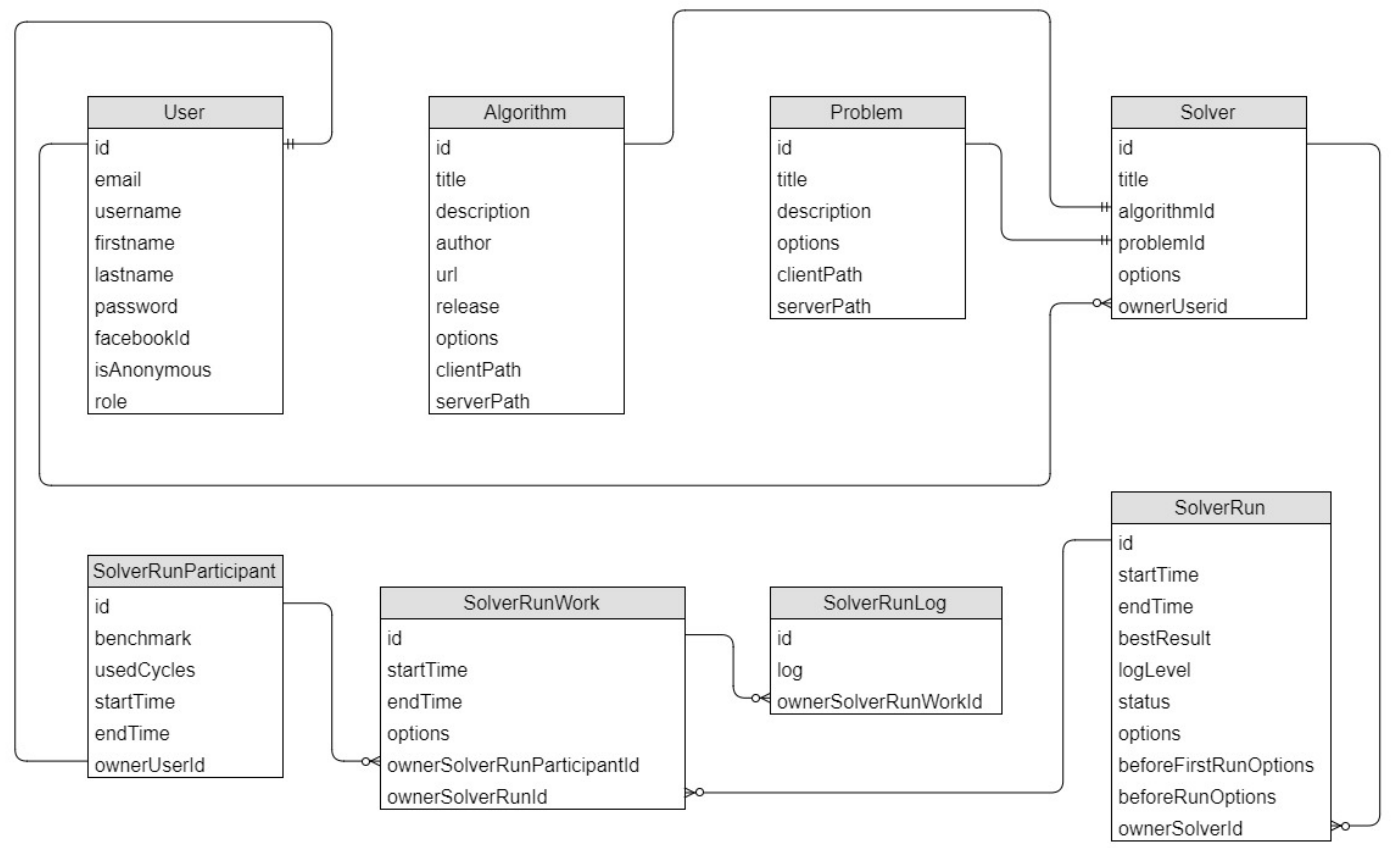

Slika 2: Podatkovni model porazdeljenega računalniškega sistema.

\subsection{Podatkovni model}

Osnova podatkovnega modela 1 sta entiteti Algorithm in Problem, kjer so shranjene njune posamezne informacije. V entiteti Solver nato definiramo, kateri algoritem bo reševal posamezni problem. Vsak novi zagon reševanja problema shranimo v entiteto SolverRun. Nova naloga, ki se pridobi od strežnika v okviru zagona algoritma, je shranjena v entiteti SolverRunWork in ima začetni ter končni čas izvajanja naloge. Lastnik vsake naloge je SolverRunParticipant, ki je končni uporabnik porazdeljenega sistema in lahko naenkrat rešuje več nalog.

\subsection{Implementacija}

Ogrodja za razvoj aplikacij niso nujno potrebna, nam pa zagotavljajo, da bo razvoj primerno strukturiran in bo potekal v skladu s poslovnimi pravili ter omogočal kasnejše nadgradnje in vzdrževanje. S ponovno uporabo generičnih modulov ogrodja, razvijalci prihranijo veliko časa in se lahko osredotočijo na druga področja. Za zaledni sistem smo izbrali ogrodje Sails.js [5], ki je zgrajeno na osnovi Node.js 4 ] strežniške tehnologije. Izbrali smo ga zaradi modularnosti, preproste uporabe in podpori realnočasovnih povezav z odjemalcem. Za izdelavo uporabniškega vmesnika smo uporabili ogrodje AngularJS 1], ki nas je prepričalo s sinhronizacijo podatkov med modelom in pogledom. Ko se podatki v modelu spremenijo, se to odraža v pogledu ter obratno. To se zgodi takoj in samodejno, kar zagotavlja, da sta model in pogled vedno posodobljena.

Za realno časovno povezavo skrbi komunikacijski protokol WebSocket, ki ustvari dvosmerni kanal za komuniciranje med odjemalcem in strežnikom. Preko povezave WebSocket je velikost posameznega poslanega paketa precej manjša, saj nima nobenega dodatnega balasta, ki je potreben pri navadnih zahtevah HTTP. Čas pošiljanja paketa na strežnik je precej krajši, saj ni potrebno vedno znova pošiljati zahtev, ker se vse pošlje po obstoječi povezavi. Odpade tudi periodično preverjanje po novih nalogah, saj to sporoči strežnik odjemalcu neposredno. Ogrodje Sails.js poskrbi, da se zahteve, poslane preko protokola HTTP, vežejo na enako akcijo kot WebSocket zahteve, kar je precej pospešilo razvoj, saj odpravi podvojenost programske kode.

Na odjemalcu se posamezna naloga izvaja na svoji niti, s katero lahko komuniciramo preko dogodkovnega vodila (angl. event bus). Z izvajanjem nalog v ozadju se izognemo obremenjevanju glavne niti, kar lahko povzroči, da se uporabniški vmesnik preneha odzivati. Vsako ustvarjeno nit po koncu izvajanja naloge prekinemo in tako sprostimo računalniške vire ter odjemalca pripravimo na nove naloge.

\section{REZULTATI}

Testiranje porazdeljenega sistema je potekalo v nadzornem okolju, kjer so sodelovali do trije odjemalci. Zaključni pogoj izvajanja algoritma lssOrel za določeno velikost problema smo definirali kot:

maksimalno število ovrednotenj $=2743,37 * 1,1456^{L}$

Enačbo smo pridobili iz testnih podatkov v 8 in je ocena, koliko ovrednotenj je potrebno, da dobimo optimalno rešitev ali njen približek. Enačbo smo potrdili kot pravilno, saj smo $\mathrm{v}$ vseh zagonih algoritma dobili najboljše znane rešitve glede na 8. za velikosti problema $L \leq 149$ (glej tabelo 4.2.

\section{ZAKLJUČEK}


Tabela 1: Doseženi rezultati s pomočjo porazdeljenega sistema. Uporabljene so naslednje oznake: $E$ - energija, $F$ - faktor (angl. merit factor), $t$ - čas v sekundah.

\begin{tabular}{|c|c|c|c|c|c|}
\hline$L$ & E & $F$ & število vrednotenj na sekundo & $t$ & največje število vrednotenj \\
\hline 7 & 3 & 8,1667 & $2,1078 \mathrm{e}+5$ & $5,4000 \mathrm{e}+1$ & $7,10420 \mathrm{e}+3$ \\
\hline 15 & 15 & 7,5000 & $1,7218 \mathrm{e}+6$ & $3,6000 \mathrm{e}+1$ & $2,10756 \mathrm{e}+4$ \\
\hline 23 & 51 & 5,1863 & $3,2107 \mathrm{e}+6$ & $3,2000 \mathrm{e}+1$ & $6,25235 \mathrm{e}+4$ \\
\hline 31 & 79 & 6,0823 & $7,6905 \mathrm{e}+6$ & $3,2000 \mathrm{e}+1$ & $1,85484 \mathrm{e}+5$ \\
\hline 39 & 99 & 7,6818 & $7,0281 \mathrm{e}+6$ & $3,2000 \mathrm{e}+1$ & $5,50265 \mathrm{e}+5$ \\
\hline 47 & 135 & 8,1815 & $7,3849 \mathrm{e}+6$ & $3,2000 \mathrm{e}+1$ & $1,63243 \mathrm{e}+6$ \\
\hline 55 & 171 & 8,8450 & $6,7895 \mathrm{e}+6$ & $3,2000 \mathrm{e}+1$ & $4,84283 \mathrm{e}+6$ \\
\hline 63 & 271 & 7,3229 & $5,9672 \mathrm{e}+6$ & $3,5000 \mathrm{e}+1$ & $1,43669 \mathrm{e}+7$ \\
\hline 71 & 275 & 9,1655 & $5,5435 \mathrm{e}+6$ & $3,7000 \mathrm{e}+1$ & $4,26214 \mathrm{e}+7$ \\
\hline 79 & 407 & 7,6671 & $5,2777 \mathrm{e}+6$ & $3,8000 \mathrm{e}+1$ & $1,26442 \mathrm{e}+8$ \\
\hline 87 & 451 & 8,3914 & $5,4171 \mathrm{e}+6$ & $7,5000 \mathrm{e}+1$ & $3,75108 \mathrm{e}+8$ \\
\hline 95 & 479 & 9,4207 & $9,6036 \mathrm{e}+6$ & $1,1900 \mathrm{e}+2$ & $1,11281 \mathrm{e}+9$ \\
\hline 97 & 536 & 8,7771 & $8,8999 \mathrm{e}+6$ & $1,8300 \mathrm{e}+2$ & $1,46045 \mathrm{e}+9$ \\
\hline 99 & 577 & 8,4931 & $8,8528 \mathrm{e}+6$ & $2,4000 \mathrm{e}+2$ & $1,91669 \mathrm{e}+9$ \\
\hline 101 & 578 & 8,8244 & $9,4152 \mathrm{e}+6$ & $2,8000 \mathrm{e}+2$ & $2,51546 \mathrm{e}+9$ \\
\hline 103 & 555 & 9,5577 & $9,3575 \mathrm{e}+6$ & $3,8200 \mathrm{e}+2$ & $3,30129 \mathrm{e}+9$ \\
\hline 105 & 620 & 8,8911 & $7,8757 \mathrm{e}+6$ & $6,3300 \mathrm{e}+2$ & $4,33261 \mathrm{e}+9$ \\
\hline 107 & 677 & 8,4557 & $9,1100 \mathrm{e}+6$ & $7,9700 \mathrm{e}+2$ & $5,68612 \mathrm{e}+9$ \\
\hline 109 & 662 & 8,9736 & $9,3342 \mathrm{e}+6$ & $8,0700 \mathrm{e}+2$ & $7,46246 \mathrm{e}+9$ \\
\hline 111 & 687 & 8,9672 & $9,2006 \mathrm{e}+6$ & $1,2170 \mathrm{e}+3$ & $9,79373 \mathrm{e}+9$ \\
\hline 113 & 752 & 8,4900 & $8,0691 \mathrm{e}+6$ & $1,7380 \mathrm{e}+3$ & $1,28533 \mathrm{e}+10$ \\
\hline 115 & 745 & 8,8758 & $7,6744 \mathrm{e}+6$ & $2,2370 \mathrm{e}+3$ & $1,68686 \mathrm{e}+10$ \\
\hline 117 & 786 & 8,7080 & $9,1235 \mathrm{e}+6$ & $2,9990 \mathrm{e}+3$ & $2,21384 \mathrm{e}+10$ \\
\hline 119 & 835 & 8,4796 & $7,1910 \mathrm{e}+6$ & $4,0850 \mathrm{e}+3$ & $2,90544 \mathrm{e}+10$ \\
\hline 121 & 844 & 8,6736 & $9,8296 \mathrm{e}+6$ & $3,9270 \mathrm{e}+3$ & $3,81310 \mathrm{e}+10$ \\
\hline 123 & 893 & 8,4709 & $5,9495 \mathrm{e}+6$ & $1,1004 \mathrm{e}+4$ & $5,00431 \mathrm{e}+10$ \\
\hline 125 & 846 & 9,2346 & $8,0048 \mathrm{e}+6$ & $8,6710 \mathrm{e}+3$ & $6,56765 \mathrm{e}+10$ \\
\hline 127 & 887 & 9,0919 & $4,8515 \mathrm{e}+6$ & $1,8681 \mathrm{e}+4$ & $8,61938 \mathrm{e}+10$ \\
\hline 129 & 920 & 9,0440 & $5,4651 \mathrm{e}+6$ & $2,4353 \mathrm{e}+4$ & $1,13121 \mathrm{e}+11$ \\
\hline 131 & 913 & 9,3981 & $6,7557 \mathrm{e}+6$ & $2,3223 \mathrm{e}+4$ & $1,48460 \mathrm{e}+11$ \\
\hline 133 & 1010 & 8,7569 & $5,0255 \mathrm{e}+6$ & $4,6720 \mathrm{e}+4$ & $1,94838 \mathrm{e}+11$ \\
\hline 135 & 1027 & 8,8729 & $8,4775 \mathrm{e}+6$ & $3,1901 \mathrm{e}+4$ & $2,55705 \mathrm{e}+11$ \\
\hline 137 & 1052 & 8,9206 & $6,0791 \mathrm{e}+6$ & $5,7210 \mathrm{e}+4$ & $3,35588 \mathrm{e}+11$ \\
\hline 139 & 1133 & 8,5265 & $1,4778 \mathrm{e}+7$ & $3,0284 \mathrm{e}+4$ & $4,40425 \mathrm{e}+11$ \\
\hline 141 & 1126 & 8,8282 & $9,2139 \mathrm{e}+6$ & $8,5836 \mathrm{e}+4$ & $5,78014 \mathrm{e}+11$ \\
\hline 143 & 1191 & 8,5848 & $4,4103 \mathrm{e}+6$ & $2,0027 \mathrm{e}+5$ & $7,58585 \mathrm{e}+11$ \\
\hline 145 & 1208 & 8,7024 & $4,3899 \mathrm{e}+6$ & $2,2762 \mathrm{e}+5$ & $9,95566 \mathrm{e}+11$ \\
\hline 147 & 1265 & 8,5411 & $2,1964 \mathrm{e}+6$ & $7,0083 \mathrm{e}+5$ & $1,30658 \mathrm{e}+12$ \\
\hline 149 & 1218 & 9,1137 & $4,0066 \mathrm{e}+6$ & $5,2562 \mathrm{e}+5$ & $1,71476 \mathrm{e}+12$ \\
\hline
\end{tabular}

V članku smo preverili, ali je možno uporabiti spletni brskalnik kot odjemalec $\mathrm{v}$ porazdeljenem računalniškem sistemu. V njem smo pognali več zagonov algoritma lssOrel, ki rešuje problem LABS. Uspeli smo potrditi vse najboljše znane rešitve, ki so bile najdene $v$ referenčnem članku [8]. Spletni brskalnik se je izkazal kot primerno nadomestilo namiznim programom, saj je preprostejši za uporabo, ima velik nabor obstoječih uporabnikov in je po naših meritvah samo za faktor 2 do 4 počasnejši od programa, ki je implementiran v programskem jeziku $\mathrm{C}++$. $\mathrm{V}$ prihodnosti se bo ta razlika zmanjšala ali morda celo izničila s prihodom novih spletnih tehnologij 7].

\section{Zahvala}

Janez Brest in Borko Bošković priznavata financiranje prispevka s strani Javne agencije za raziskovalno dejavnost Republike Slovenije, raziskovalni program P2-0041 - Računalniški sistemi, metodologije in inteligentne storitve.

\section{LITERATURA}

[1] AngularJS .https://angularjs.org/, 2017. [Na spletu; dostopano 14-08-2017].

[2] Golem worldwide supercomputer https://golem.network/, 2017. [Na spletu; dostopano 14-08-2017].

[3] Great Internet Mersenne Prime Search . https://www .mersenne.org/various/works.php/ 2017. [Na spletu; dostopano 14-08-2017].

[4] Node.js . https://nodejs.org/en/about/, 2017. [Na spletu; dostopano 14-08-2017].

[5] Sails.js .http://sailsjs.com//, 2017. [Na spletu; dostopano 14-08-2017].

[6] SETI@home . https://setiathome.berkeley.edu/sah_about.php/, 2017. [Na spletu; dostopano 14-08-2017].

[7] WebAssembly ·http://webassembly.org/, 2017. [Na spletu; dostopano 14-08-2017].

[8] B. Bosković, F. Brglez, and J. Brest.

Low-autocorrelation binary sequences: On improved merit factors and runtime predictions to achieve them. Applied Soft Computing, 56(2):262-285, 2017.

[9] J. L. A. M. A. P. J. Merelo, P. Castillo. Asynchronous distributed genetic algorithms with javascript and json In WCCI 2008 Proceedings, page 1372-1379. IEEE Press, March 2008 